\title{
Acetylation of woody lignocellulose: significance and regulation
}

\author{
Prashant Mohan-Anupama Pawar ${ }^{1}$, Sanna Koutaniemi ${ }^{2}$, Maija Tenkanen$^{2}$ and Ewa J. Mellerowicz ${ }^{1}$ * \\ Department of Forest Genetics and Plant Physiology, Swedish University of Agricultural Sciences, Umea, Sweden \\ ${ }^{2}$ Department of Food and Environmental Sciences, University of Helsinki, Helsinki, Finland
}

\section{Edited by:}

Maurice Bosch, Aberystwyth

University, UK

Reviewed by:

Peter Ulvskov, Copenhagen

University, Denmark

Paul Gatenholm, Chalmers University

of Technology, Sweden

*Correspondence:

Ewa J. Mellerowicz, Department of Forest Genetics and Plant Physiology, Swedish University of Agricultural Sciences, S901-83 Umeå, Sweden. e-mail:ewa.mellerowicz@s/u.se
Non-cellulosic cell wall polysaccharides constitute approximately one quarter of usable biomass for human exploitation. In contrast to cellulose, these components are usually substituted by $O$-acetyl groups, which affect their properties and interactions with other polymers, thus affecting their solubility and extractability. However, details of these interactions are still largely obscure. Moreover, polysaccharide hydrolysis to constituent monosaccharides is hampered by the presence of $O$-acetyl groups, necessitating either enzymatic (esterase) or chemical de-acetylation, increasing the costs and chemical consumption. Reduction of polysaccharide acetyl content in planta is a way to modify lignocellulose toward improved saccharification. In this review we: (1) summarize literature on lignocellulose acetylation in different tree species, (2) present data and current hypotheses concerning the role of $\mathrm{O}$-acetylation in determining woody lignocellulose properties, (3) describe plant proteins involved in lignocellulose $O$-acetylation, (4) give examples of microbial enzymes capable to de-acetylate lignocellulose, and (5) discuss prospects for exploiting these enzymes in planta to modify xylan acetylation.

Keywords: cell wall, wood, biofuel, saccharification, $O$-acetylation, hemicellulose, acetyl esterase

\section{OCCURRENCE OF O-ACETYLATION IN LIGNOCELLULOSE}

$O$-acetyl and methyl esterification are the most common substitutions in different cell wall matrix polysaccharides (Figure 1). While the role of methyl esterification in plant cell walls has been a focus of many studies, that of $O$-acetylation has received much less attention in the past. $O$-acetylation may occur on the backbones or branches of many cell wall polymers (recently reviewed by Gille and Pauly, 2012), but the nature of acetylated polymer and the extent of acetylation differ between species, tissues and types of cell walls (Figure 1; Table 1)

In the type I primary walls of softwoods and hardwoods, pectins [homogalacturonan (HG), rhamnogalacturonan I (RGI), and rhamnogalacturonan II] and xyloglucan (XG) are the main sources of $O$-acetyl groups, whereas in the type II primary walls of grasses, the main $O$-acetylated polymer is glucuronoarabinoxylan. The largest pool of acetyl residues in lignocellulose, however, comes from the secondary cell walls since they constitute the bulk of biomass. O-acetylation in glucuronoxylan and glucomannan, the main hemicelluloses in secondary cell walls of hardwoods and softwoods, respectively, is found on the $\mathrm{O}-2$ and/or $\mathrm{O}-3$ positions of the backbone xylopyranosyl or mannopyranosyl residues (Timell, 1967; Teleman etal., 2000; Capek etal., 2002; Willför et al., 2003; Gonçalves et al., 2008; Naran et al., 2009). The minor hemicelluloses are also xylan or mannan-based but more highly branched polymers: galactoglucomannan in hardwoods and glucuronoarabinoxylan in softwoods. Only the mannan is acetylated, suggesting that the function of xylan differs between softwoods and hardwoods.

Typical positions of acetyl groups in these polymers are shown in Figure 1, but species-specific positions also may exist (Hayashi,
1989; Pauly, 1999; Jacobs etal., 2002; Jia etal., 2005), and spontaneous migration of acetyl group between the neighboring free hydroxyls is possible (Kabel etal., 2003; Mastihubová and Biely, 2004). Acetylation level is described as degree of acetylation (DA), which is the molecular ratio between the total content of acetyl groups and the total content of monomers that can bear them. DA varied from 0.60 to 0.75 in aspen wood glucuronoxylan and from 0.3 to 0.4 in (galacto)glucomannan in the wood of aspen, birch and spruce (Teleman et al., 2000, 2003). Therefore the overall acetyl content is lower in softwoods than in hardwoods. Existence of specific domains with respect to acetylation, as known for pectin methyl esterification, is an intriguing possibility (Jacobs et al., 2002; Ralet et al., 2008).

Acetyl groups are also found in lignin, linked to the gammacarbon of the aliphatic side chain of lignin $S$ and $G$ monomers and can be very variable (Del Rio et al., 2007). The highest levels, up to DA 0.8 of S monomers, are found in extraxylary fibers in jute, abaca, and kenaf. In hardwood xylem, lignin acetylation varies between 1 and $50 \%(\mathrm{w} / \mathrm{w})$ whereas in softwood xylem it has not been reported. The function and consequences of such variability in lignin acetylation are unknown.

\section{LIGNOCELLULOSE PROPERTIES AFFECTED BY POLYSACCHARIDE ACETYLATION POLYMER ACETYLATION AFFECTS ITS INTERACTIONS WITH POLAR MOLECULES}

Lignocellulose polysaccharides can be de-acetylated by alkali and re-acetylated by acetic anhydride, providing materials for studying of physico-chemical properties affected by acetylation. 


\section{A O-acetyl group Methyl ester group}<smiles>COC(C)=O</smiles>
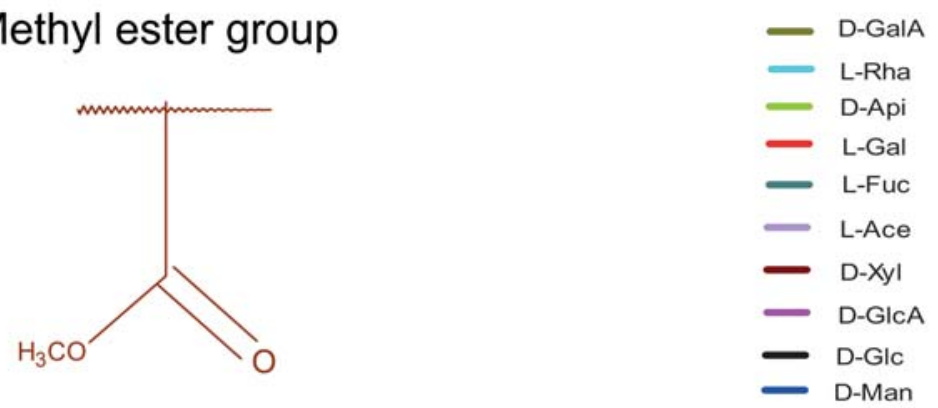

B
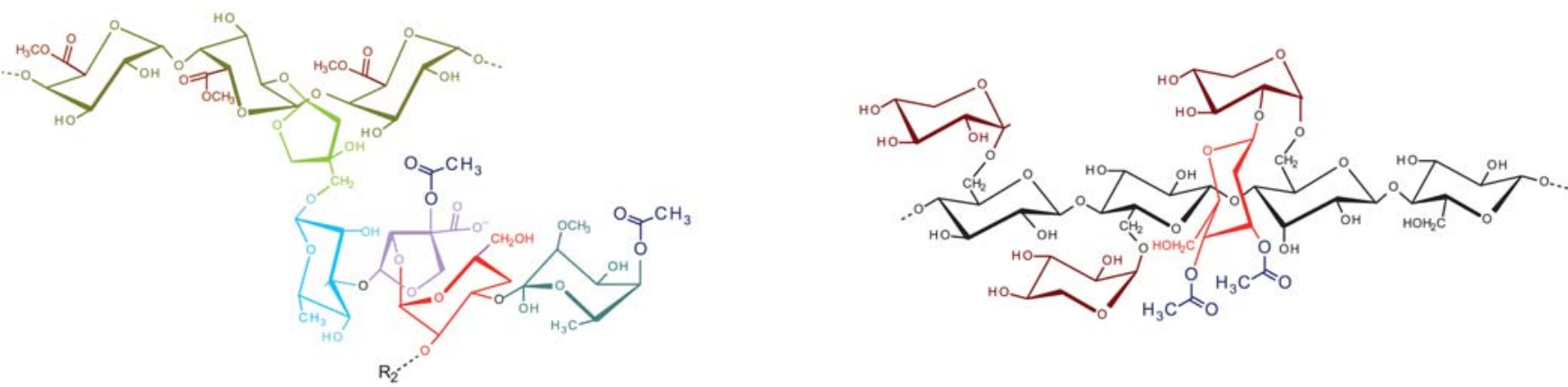

Rhamnogalacturonan II

(Galacto)Xyloglucan
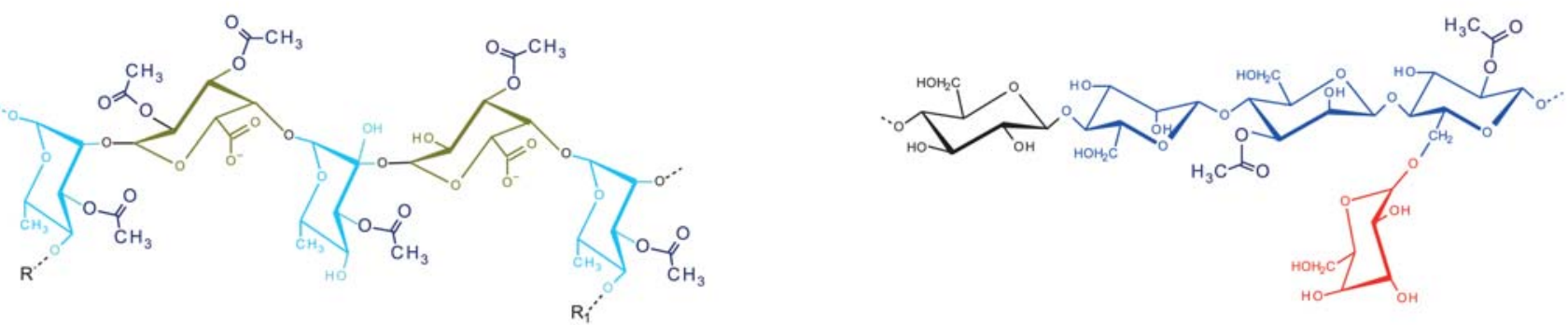

Rhamnogalacturonan I

Galactoglucomannan
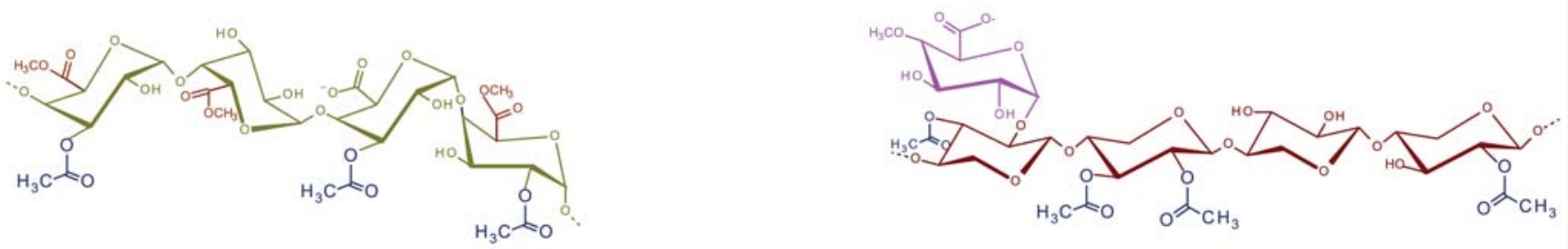

Homogalacturonan

Glucuronoxylan

FIGURE 1 | $\boldsymbol{O}$-acetylation of cell wall polysaccharides. (A) Generic representation of $\mathrm{O}$-acetyl group as found at different $-\mathrm{OH}$ positions in many cell wall polysaccharides. Note the structural similarity between O-acetyl-and methyl ester-groups that decorate carboxylic acid residues in polygalacturonic acid. (B) Occurrence of $O$-acetyl groups in cell wall matrix polysaccharides Noragen etal., 1986; Pauly and Scheller, 2000; MacKinnon et al., 2002; Teleman etal., 2002; Glushka etal., 2003; O'Neill etal., 2004; Ralet et al., 2005). 
Table 1 | Acetyl contents in lignocellulose from some common woody lignocelluloses in comparison to wheat straw.

\begin{tabular}{lll}
\hline Species & \% d.w. & Reference \\
\hline Wheat (straw) & 2.2 & Sumi (1964) \\
Populus tremuloides Michx. (wood) & 3.7 & $\begin{array}{c}\text { Timell (1967); } \\
\text { Sjöström (1993) }\end{array}$ \\
Eucalyptus globulus Labill. (wood) & 3.5 & Cetinkol et al. (2010) \\
Fagus. grandifolia Ehrh. (wood) & 3.9 & Timell (1967) \\
Betula papyrifera Marsh. (wood) & 4.4 & Timell (1967) \\
Picea glauca Moench. (wood) & 1.3 & Laffend (1967); \\
& & Timell (1967) \\
Pinus strobus L. (wood) & 1.2 & Timell (1967) \\
Abies balsamea Mill. (wood) & 1.5 & Timell (1967) \\
\hline
\end{tabular}

Such comparisons show that de-acetylated xylan absorbs more moisture than highly acetylated xylan because it offers more hydrogen bonding to water molecules (Grondahl et al., 2003). The weakly acetylated xylan (DA $\sim 0.5)$ is totally soluble in water, whereas the totally acetylated xylan (DA 2.0) only dissolves in non-polar solvents like chloroform or polar aprotic solvents like dimethyl sulfoxide. The non-acetylated xylan (DA 0 ) is only partially soluble in hot water, due to spontaneous intra-molecular hydrogen bonding. De-acetylation of xylan also facilitates its bonding to cellulose (Kabel et al., 2007), whereas its acetylation could be a mean of increasing its interaction with hydrophobic substances like plastic used for making composite woodbased products (Lisperguer et al., 2007) or naturally occurring lignin.

\section{WOODY BIOMASS DE-ACETYLATION IS IMPORTANT FOR PULPING, SACCHARIFICATION AND FERMENTATION}

Wood is de-acetylated during the initial phases of chemical pulping, which consumes most of alkali during Kraft cooking (Zanuttini etal., 2003), and results in the accumulation of acetate in the spent liquor (Sjöström, 1993). Following deacetylation, fibers swell, which improves their ion transport capacity and facilitates pulping (Sumi, 1964). In mechanical pulping, de-acetylation takes place after the refining step during the alkaline peroxide bleaching. In both pulping processes, de-acetylation of hemicelluloses improves their adsorption to cellulose, which in turn increases the yield and the tensile strength of paper (Laffend, 1967; Zanuttini etal., 2005; Konn etal., 2006).

To convert woody biomass to biofuels, such as bioethanol or biogas, the polysaccharides need to be first hydrolysed to monosaccharides, which are subsequently fermented to ethanol or methane. During saccharification, acetyl groups in xylans and mannans create steric hindrance for binding of many hydrolytic enzymes, which limits the extent of hydrolysis (recently reviewed by Biely (2012). For example, the action of endoxylanases is partially or completely hindered by acetyl groups (Biely etal., 1986; Grohmann etal., 1989). Sugar yields of $\beta$-xylosidases, $\beta$-mannosidases, and $\beta$-glucosidases are increased by the addition of suitable esterases, indicating that these hydrolytic enzymes cannot release acetylated terminal residues from hemicellulosic oligosaccharides. Acetylation of xylan also limits its hydrolysis by acid (Chen et al., 2012). De-acetylation of hemicelluloses is therefore a prerequisite for their saccharification, which in turn is important for opening cellulose surface to cellulolytic enzymes (Vazquez etal., 2001; Selig et al., 2009; Zhang et al., 2011).

Chemical de-acetylation of wood is stoichiometric, thus $100 \mathrm{~g}$ of aspen wood requires $\sim 4 \mathrm{~g}$ of $\mathrm{KOH}$ for complete de-acetylation (Kong et al., 1992). Diluted alkali removed acetyl esters without affecting lignin or xylan, which increased total monosaccharide yield approximately fourfold. In similar experiments with American aspen, up to $90 \%$ de-acetylation improved cellulose and xylan conversion two and sevenfold, respectively (Holtzapple and Chang, 2000). Chemical de-acetylation, which is done prior the enzymatic hydrolysis, lowers the solubility and extractability of xylans and mannans limiting their hydrolysis (Tenkanen, 1995). In contrast, the enzymatic de-acetylation does not induce such undesirable changes since it is carried out simultaneously with saccharification.

De-acetylation of lignocellulose results in the accumulation of acetate in the medium, which depending on the $\mathrm{pH}$, might be in a protonated form. Small amounts of acetic acid stimulate the metabolism of common yeast-strains (Maiorella et al., 1983; Almeida et al., 2007), but higher concentrations, starting at the levels typical for softwood processing, inhibit yeast growth and fermentation (Olsson and Hahn-Hägerdal, 1996; Ranatunga et al., 1997; Helle et al., 2003).

\section{ACETYLATION OF SECONDARY BUT NOT PRIMARY WALLS INCREASES MECHANICAL STRENGTH}

While the high hemicellulose acetylation is disadvantageous for pulping and biofuel production, it is often desirable in solid wood products. Wood acetic anhydride treatment, resulting in $\sim 5-15 \%$ of weight gain, increases wood mechanical strength (modulus of elasticity and rupture) in both tension and compression experiments, but higher levels of acetylation are damaging (Ramsden et al., 1997; Papadopoulos and Pougioula, 2010). Interestingly, the acetylation is initially introduced to the secondary wall layers where hydroxyl groups of hemicelluloses are likely the main reactants, whereas prolonged treatment introduces acetyl to the middle lamella where pectins and lignin are the main targets (Rowell, 2009). Most likely it is the acetylation of xylan and mannan in secondary wall layers that is responsible for the increased stiffness, possibly by allowing more hydrophobic interactions with lignin.

Such a mechanism is not possible in non-lignified primary walls. Indeed, it has been shown that overexpression of pectin acetyl esterase (PAE) inhibited cell elongation in tobacco (Gou et al., 2012) and led to stiffer cell walls in potato tubers based on mechanical stress/strain experiments (Orfila et al., 2012). Moreover, primary cell wall acetylation was negatively correlated with cell adhesion (Liners et al., 1994). Since pectin acetylation, similarly, to methyl esterification, interferes with binding of calcium to polygalacturonic acid and formation of "egg-box" domains in 
cell wall (Ralet et al., 2003), pectin acetylation decreases cell wall stiffness.

\section{ACETYLATION AFFECTS WOOD BIOTIC RESISTANCE}

Since acetylation of xylan and mannan hinders their hydrolysis, chemical acetylation of wood has been used to increase its durability and resistance to fungi, bacteria, and termites (Peterson and Thomas, 1978; Mohebby, 2003; Rowell, 2009). It was therefore surprising to find that reduced acetylation in different polymers, XG and pectins - in rwa2 mutants, xylan - in lines overexpressing acetyl xylan esterase (AXE) from family carbohydrate esterase 1 (CE1), and pectin - in lines overexpressing rhamnogalacturonan acetyl esterase (RGAE), induced resistance to necrotrophic fungi (Manabe et al., 2011; Pogorelko et al., 2013). Moreover, whereas digestibility of pectins by Aspergillus pectinase was actually reduced by their de-acetylation (Gou et al., 2012), digestibility of cell walls of plants expressing either PAE or RGAE by pectinase/PME mixture was increased (Orfila et al., 2012; Pogorelko et al., 2013). Overexpressed esterases were shown to activate plant acetylation and defense pathways, and it has been proposed that the cell wall fragments generated as a result of deacetylation may trigger the activation of plant innate immune responses (Pogorelko et al., 2013). Clearly, more studies are needed to understand how acetylation of different polymers affects their digestibilities in vivo and in vitro by different hydrolases to gain understanding of the role of their acetylation in biotic stress resistance.

\section{ENZYMES DE-ACETYLATING LIGNOCELLULOSE POLYSACCHARIDES \\ DE-ACETYLATION OF XYLAN AND MANNAN}

Polymeric xylan and xylo-oligosaccharides are de-acetylated by AXEs (EC 3.1.1.72). Short xylo-oligosaccharides can be also deacetylated by non-specific acetyl esterases (AE; EC 3.1.1.6), which act mainly on the non-reducing end residues (Poutanen etal., 1990; Linden etal., 1994). AXEs and AEs have been found in wood-degrading fungi and bacteria (Biely et al., 1985; Dupont et al., 1996; Biely, 2012). The occurrence of true AXEs in plants has not been reported, although poplar PAE1 had some activity toward acetylated xylan (Gou et al., 2012).

Acetyl xylan esterases fall presently into eight of the $16 \mathrm{CE}$ families (http://www.cazy.org/), including CE1-CE7, and CE16 (Table 2; Dodd and Cann, 2009; Biely, 2012; Gou et al., 2012). Most CE1-CE7 enzymes are serine esterases having Ser-His-Asp(Glu) triad or Ser-His diad in their active sites and use the catalytic mechanism with the formation of enzyme-Ser complex (acetylation), followed by the de-acetylation by activated water molecule. CE4 enzymes have a unique, Asp-His and divalent cation-dependent activity (Taylor et al., 2006; Biely, 2012).

Different AEs and AXEs may exhibit preferences to different acetyl positions (Christov and Prior, 1993; Linden et al., 1994; Biely, 2012). For example, CE1, CE4, and CE5 AXEs have preference for position $\mathrm{O}-2$, CE16 AEs for positions $\mathrm{O}-3$ and $\mathrm{O}-4$ (Biely et al., 2011) and CE2 AXEs for position O-6 in hexoses (Topakas etal., 2010). Many CE1 and CE2 AXEs have broad specificities for xylan and mannan. Acetyl glucomannan esterase (AGME, EC 3.1.1.- ) activity was shown in Aspergillus sp., and the enzyme was also capable of slow de-acetylation of xylan (Tenkanen et al., 1995). CE family for this enzyme remains to be identified.

\section{DE-ACETYLATION OF PECTINS}

Pectin acetyl esterases (EC 3.1.1.-) were found in plant and microbial species (Williamson, 1991; Breton et al., 1996; Shevchik and Hugouvieux-Cotte-Pattat, 1997, 2003; Gou et al., 2012). Plant PAEs belong to family CE13 and are secreted enzymes acting on $\mathrm{O}-2$ and $\mathrm{O}-3$ acetyl in HG. Arabidopsis and Populus have 12 and 9 CE13 members, respectively (Geisler-Lee et al., 2006). Genomic sequencing identified similar proteins in animals and bacteria, but corresponding activities have not been characterized. Bacterial PAEs of Erwinia chrysanthemi PaeX and PaeY, acting on demethylated oligomeric and polymeric HG, respectively, are classified in CE10 (Shevchik and Hugouvieux-Cotte-Pattat, 1997, 2003).

Rhamnogalacturonan acetyl esterase (EC 3.1.1.86) deacetylates RGI at GalA $\mathrm{O}-2$ and $\mathrm{O}-3$ positions and belongs to CE12 (Molgaard etal., 2000). This activity has been shown in Aspergillus aculeatus (Schols etal., 1990), and in bacteria where it has broad substrate specificity including acetylated xylan and cephalosporin C (Martinez-Martinez etal., 2008; Navarro-Fernandez et al., 2008).

\section{BIOSYNTHESIS OF ACETYLATED POLYSACCHARIDES IN PLANTS}

$\mathrm{O}$-acetylation of plant cell wall-polysaccharides takes place in the Golgi. In the case of HG, RGI, and XG, acetyl-CoA has been identified as a donor substrate (Pauly and Scheller, 2000). Proteins involved in polysaccharide acetylation are conserved in proand eukaryotes (Gille and Pauly, 2012). In fungi, animals and Gram-positive bacteria, the acetyl transfer to extra-cytoplasmic compartment and catalysis are performed by a single multifunctional protein Cas1p identified first in Cryptococcus neoformans. Caslp has a set of 12 transmembrane domains (called Cas1p domain) that are proposed to form a channel for acetyl-CoA transfer, and two other domains, TRICHOME-BIREFRINGENCELIKE (TBL)-domain and DUF231 located at the extra-cytoplasmic side, that are involved in esterification and are conserved in serine esterases/lipases of SGNH superfamily including AXEs (Dodd and Cann, 2009).

In plants, two separate gene families are needed for acetylation of cell wall polymers. REDUCED WALL ACETYLATION (RWA) family, which has the Casp1 domain (Lee et al., 2011; Manabe et al., 2011), and TBL family, which has TBL and DUF231 domains (Anantharaman and Aravind, 2010; Bischoff etal., 2010a,b; Gille et al., 2011a).

Arabidopsis RWA family has four members. RWA1, RWA3, and RWA4 were suggested to redundantly regulate acetylation in secondary walls (Lee et al., 2011) whereas RWA2 was shown to be responsible for acetylation of XG and pectin (Manabe et al., 2011). Quadruple rwal/2/3/4 mutants show $42 \%$ loss of acetyl groups in xylan and 40\% reduction in stem acetyl content (Lee et al., 2011). These results indicate that RWA regulates acetylation in several polymers and is partially redundant with some other presently unknown proteins. Arabidopsis TBL family has 45 members (Anantharaman and Aravind, 2010). Two of 
Table 2 | Examples of enzymes deacetylating plant cell wall poly and oligosaccharides.

\begin{tabular}{|c|c|c|c|c|c|c|}
\hline CAZY & Species & Activity ${ }^{1}$ & Reference & pH & Protein name(s) & Accession number \\
\hline \multirow[t]{3}{*}{ CE1 } & Aspergillus awamori & AXE & Koseki etal. (2005) & $6-7$ & AXEA & BAA13434 \\
\hline & Aspergillus niger & AXE & Kormelink et al. (1993) & 5.5 & AXEA & CAK46215 \\
\hline & Penicillium purpurogenum & AXE & Gordillo et al. (2006) & 6 & AXEI & AAM93261 \\
\hline CE2 & Cellvibrio japonicus & AXE and AGME & Montanier et al. (2009) & 7 & AXE2B, CE2C & ACE85140 \\
\hline CE3 & Clostridium thermocellum & AXE & Correia et al. (2008) & 7 & CES3 & ABN52033 \\
\hline CE4 & Streptomyces lividans & AXE & Dupont et al. (1996) & $6-7$ & AXEA & AAC06115 \\
\hline CE5 & Penicillium purpurogenum & AXE & Egaña et al. (1996) & 6 & AXEII & AAC39371 \\
\hline CE6 & Fibrobacter succinogenes & AXE & Yoshida et al. (2010) & 7.5 & AXE6A & AF180369 \\
\hline \multirow[t]{2}{*}{ CE7 } & Thermoanaerobacterium & AXE and CCD & Shao and Wiegel (1995) & 6 & AXE1 & AF001926 \\
\hline & Bacillus pumilus & AXE and CCD & Degrassi etal. (2000) & 7 & AXE & AJ249957 \\
\hline \multirow[t]{2}{*}{ CE10 } & Erwinia chrysanthemi & PAE & $\begin{array}{l}\text { Shevchik and } \\
\text { Hugouvieux-Cotte-Pattat (1997) }\end{array}$ & 8 & PAEY & CAA70971 \\
\hline & Erwinia chrysanthemi & PAE enhanced by PEL & $\begin{array}{l}\text { Shevchik and } \\
\text { Hugouvieux-Cotte-Pattat (2003) }\end{array}$ & 8.5 & PAEX & CAD45188 \\
\hline CE16 & Trichoderma reesei & $\begin{array}{l}\text { AE enhanced by xylanases } \\
\text { and mannanases }\end{array}$ & $\begin{array}{l}\text { Poutanen etal. (1990); } \\
\text { Li etal. (2008) }\end{array}$ & 5.5 & AES1 & ABI34466 \\
\hline
\end{tabular}

${ }^{1} A E$, acetyl esterases (AE; EC 3.1.1.6); AGME, acetyl glucomannan esterase (EC 3.1.1.-); AXE, acetyl xylan esterase (EC 3.1.1.72); CCD, cephalosporin C deacetylase (EC 3.1.1.41); RGAE, rhamnogalacturonan acetyl esterase (EC 3.1.1.86); PAE, pectin acetyl esterase (EC 3.1.1.); PEL, pectate lyase (EC 4.2.2.2).

them, TBL-27/AXY4 and TBL-22/AXY4L, are required for XG acetylation in vegetative tissues and in seeds, respectively, but do not affect acetylation of pectins, xylan or mannan (Gille et al., 2011a). Deep sequencing Amorphophallus konjac corm indicated that proteins similar to AtTBL-25 and AtTBL-26 might be mannan $O$-acetyltransferases (Gille et al., 2011b). Recently, the main putative xylan acetyl transferase has been identified as AtTBL29/ESKIMO1 (Xiong et al., 2013). The eskimo1 mutants had 60\% reduced acetylation of xylan and a smaller reduction in mannan acetylation but pectin or XG acetyl content was not affected. These results support the proposal that the TBL-family members encode acetyl transferases acting on specific polymers (Gille et al., 2011a; Gille and Pauly, 2012).

\section{PROSPECTS FOR MODIFYING POLYSACCHARIDE O-ACETYLATION IN PLANTS}

Different roles are emerging for acetylation in different plant polymers, for example regarding mechanical properties of pectin and xylan, as we have discussed here. Genetic tools are now in place to systematically modify acetylation in specific polysaccharides (but not yet in lignin), and to study mechanical properties of such modified plants. These studies, supplemented by in vitro analyses of the rheological properties of polymers, would provide a framework for understanding molecular mechanisms operating in cell walls that are affected by polymer acetylation.

Considering the high impact of polysaccharide acetylation for downstream utilization of woody lignocellulose, it appears 
that DA of different polymers is an important target for the feedstock improvement. Surprisingly, the knowledge of natural variation of these traits in tree species is virtually missing. One major obstacle for gathering such data and including acetylation traits in conventional breeding programs is the shortage of high throughput analytical tools for detailed analysis of degree and position of acetylation in different plant cell wall polysaccharides.

However, genetic engineering of feedstocks with altered acetylation seems feasible in a near future. Based on studies published since 2011, it appears that moderate (by $\sim 20 \%$ ) reduction of general acetylation levels, in planta by mutating biosynthetic genes (Lee et al., 2011; Manabe et al., 2011) or by introducing an AXE to the apoplast for post-synthetic acetyl removal (Pogorelko et al., 2011) is tolerated by herbaceous species, however, too strong deacetylation of xylan might lead to undesirable molecular changes in cell wall (Poutanen et al., 1990) resulting in growth defects as observed in the rwa1/2/3/4 and tbl-29 mutants (Lee et al., 2011; Xiong et al., 2013). Also, post-synthetic de-acetylation of pectins was shown to affect stem and reproductive organ growth (Gou et al., 2012). Thus, the kind of polymer affected, and the degree of de-acetylation matter for plant performance and might need to be optimized. Increased acetylation in planta, which might be desirable in solid wood products, has not been so far demonstrated. The overexpression of TBL-29 did not result in higher acetyl content in Arabidopsis (Xiong et al., 2013). Thus it is not yet known if increase of cell wall acetylation can be obtained and tolerated by plants.

\section{REFERENCES}

Almeida, J. R. M., Modig, T., Petersson, A., Hahn-Hägerdal, B., Liden, G., and Gorwa-Grauslund, M. F. (2007). Increased tolerance and conversion of inhibitors in lignocellulosic hydrolysates by Saccharomyces cerevisiae. J. Chem. Technol. Biotechnol. 82, 340-349.

Anantharaman, V., and Aravind, L. (2010). Novel eukaryotic enzymes modifying cell-surface biopolymers. Biol. Direct 5, 1.

Biely, P. (2012). Microbial carbohydrate esterases deacetylating plant polysaccharides. Biotechnol. Adv. 30, 15751588.

Biely, P., Mackenzie, C. R., Puls, J., and Schneider, H. (1986). Cooperativity of esterases and xylanases in the enzymatic degradation of acetyl xylan. Bio-Technology 4, 731-733.

Biely, P., Mastihubova, M., Tenkanen, M., Eyzaguirre, J., Li, X.-L., and Vrsanska, M. (2011). Action of xylan deacetylating enzymes on monoacetyl derivatives of 4-nitrophenyl glycosides of beta-D-xylopyranose and alpha-Larabinofuranose. J. Biotechnol. 151, 137-142.

Biely, P., Puls, J., and Schneider, H. (1985). Acetyl xylan esterases in fungal cellulolytic systems. FEBS Lett. $186,80-84$.

Bischoff, V., Nita, S., Neumetzler, L., Schindelasch, D., Urbain, A., Eshed, R., etal. (2010a). TRICHOME BIREFRINGENCE and its homolog AT5G01360 encode plant-specific DUF231 proteins required for cellulose biosynthesis in Arabidopsis. Plant Physiol. 153, 590-602.

Bischoff, V., Selbig, J., and Scheible, W. R. (2010b). Involvement of TBL/DUF231 proteins into cell wall biology. Plant Signal. Behav. 5, 10571059.

Breton, C., Bordenave, M., Richard, L., Pernollet, J. C., Huet, J. C., Perez, S., et al. (1996). PCR cloning and expression analysis of a cDNA encoding a pectinacetylesterase from Vigna radiata L. FEBS Lett. 388 , 139-142.

Capek, P., Alfoldi, J., and Liskova, D. (2002). An acetylated galactoglucomannan from Picea abies L. Karst. Carbohydr. Res. 337, 1033-1037.

Cetinkol, O. P., Dibble, D. C., Cheng, G., Kent, M. S., Knierim, B., Auer, M., et al. (2010). Understanding the impact of ionic liquid pretreatment on eucalyptus. Biofuels 1, $33-46$.

Little is known about the performance of acetyl-modified plants in various applications or about the goals for acetyl optimisation. For example, extractability of polymers is likely a key parameter that is affected by acetylation, and has not received much attention. Saccharification is another matter - although xylan acetylation restricts its hydrolysis, opposite results have been obtained with pectin (Gou et al., 2012). Only a few reports exist on acetyl-modified plants where the cell wall context and type of pretreatment come into play: saccharification yields of rwa1/2/3/4 mutants were not increased compared to wild type in tests without pretreatment (Lee et al., 2011) whereas tbl-29 mutant showed a $10 \%$ decrease in glucose yield per cell wall mass (Xiong etal., 2013). However, taking into account $\sim 20 \%$ reduction in cellulose content in tbl-29 would reveal that a higher proportion of cellulose was hydrolysed in the mutant than in wild type. $\sim 20 \%$ reduction in acetyl content in plants overexpressing AXE did not improve saccharification after acid pretreatment (Pogorelko et al., 2011). Clearly, analysis of a range of transgenic lines with different levels of de-acetylation, using standardized protocols is needed to optimize their acetyl level taking into account both plant and lignocellulose performance in a process.

\section{ACKNOWLEDGMENTS}

We thank Dr. Markus Pauly for sending us his manuscript prior publication. The work was supported by the grants form FORMAS and VR to Ewa J. Mellerowicz, and the BIOIMPROVE program.

Chen, X., Shekiro, J., Franden, M. A. Wang, W., Zhang, M., Kuhn, E., et al. (2012). The impacts of de-acetylation prior to dilute acid pretreatment on the bioethanol process. Biotechnol. Biofuels 5, 8 .

Christov, L. P., and Prior, B. A. (1993). Esterases of xylandegrading microorganisms - production, properties, and significance. Enzyme Microb. Technol. 15 , 460-475.

Correia, M. A. S., Prates, J. A. M., Bras, J., Fontes, C. M. G. A., Newman, J. A., Lewis, R. J., et al. (2008). Crystal structure of a cellulosomal family 3 carbohydrate esterase from Clostridium thermocellum provides insights into the mechanism of substrate recognition. J. Mol. Biol. 379, 64-72.

Dalrymple, B. P., Cybinski, D. H., Layton, I., McSweeney, C. S. Xue, G. P., Swadling, Y. J., et al. (1997). Three Neocallimastix patriciarum esterases associated with the degradation of complex polysaccharides are members of a new family of hydrolases. Microbiology 143, 26052614.

Degrassi, G., Kojic, M., Ljubijankic, G., and Venturi, V. (2000). The acetyl xylan esterase of Bacillus pumilus belongs to a family of esterases with broad substrate specificity. Microbiology 146, 1585-1591.

Del Rio, J. C., Marques, G., Rencoret, J., Martinez, A. T., and Gutierrez, A. (2007). Occurrence of naturally acetylated lignin units. J. Agric. Food Chem. 55, 5461-5468.

Dodd, D., and Cann, I. K. O. (2009). Enzymatic deconstruction of xylan for biofuel production. Glob. Change Biol. Bioenergy 1, 2-17.

Dupont, C., Daigneault, N., Shareck, F., Morosoli, R., and Kluepfel, D. (1996). Purification and characterization of an acetyl xylan esterase produced by Streptomyces lividans. Biochem. J.319, 881-886.

Egaña, L., Gutiérrez, R., Caputo, V., Peirano, A., Steiner, J., and Eyzaguirre, J. (1996). Purification and characterization of two acetyl xylan esterases from Penicillium purpurogenum. Biotechnol. Appl. Biochem. 24, 33-39.

Geisler-Lee, J., Geisler, M., Coutinho, P. M., Segerman, B., Nishikubo, N., Takahashi, J., et al. (2006). Poplar carbohydrate-active enzymes. Gene identification and expression analyses. Plant Physiol. 140, 946-962. 
Gille, S., De Souza, A., Xiong, G., Benz, M., Cheng, K., Schultink, A., et al. (2011a). O-acetylation of Arabidopsis hemicellulose xyloglucan requires AXY4 or AXY4L, proteins with a TBL and DUF231 domain. Plant Cell 23, 4041-4053.

Gille, S., Cheng, K., Skinner, M. E., Liepman, A. H., Wilkerson, C. G., and Pauly, M. (2011b). Deep sequencing of voodoo lily (Amorphophallus kon$j a c)$ : an approach to identify relevant genes involved in the synthesis of the hemicellulose glucomannan. Planta 234, 515-526.

Gille, S., and Pauly, M. (2012). O-acetylation of plant cell wall polysaccharides. Front. Plant Sci. 3:12. doi: 10.3389/ fpls.2012.00012

Glushka, J. N., Terrell, M., York, W. S., O’Neill, M. A., Gucwa, A., Darvill, A. G., etal. (2003). Primary structure of the 2-O-methyla-L-fucose-containing side chain of the pectic polysaccharide, rhamnogalacturonan II. Carbohydr. Res. 38, 341-352.

Gonçalves, V. M. F., Evtuguin, D. V., and Domingues, M. R. M. (2008). Structural characterization of the acetylated heteroxylan from the natural hybrid Paulownia elongatal Paulownia fortunei. Carbohydr. Res. 343, 256-266.

Gordillo, F., Caputo, V., Peirano, A., Chavez, R., Van Beeumen, J., Vandenberghe, I., et al. (2006). Penicillium purpurogenum produces a family 1 acetyl xylan esterase containing a carbohydrate-binding module: characterization of the protein and its gene. Mycol. Res. 110, 1129-1139.

Gou, J.-Y., Miller, L. M., Hou, G., Yu, X.-H., Chen, X.-Y., and Liu, C.-J. (2012). Acetylesterase-mediated de-acetylation of pectin impairs cell elongation, pollen germination, and plant reproduction. Plant Cell 24, 50-65.

Grohmann, K., Mitchell, D. J., Himmel, M. E., Dale, B. E., and Schroeder, H. A. (1989). The role of ester groups in resistance of plant-cell wall polysaccharides to enzymatichydrolysis. Appl. Biochem. Biotechnol. 20-21, 45-61.

Grondahl, M., Teleman, A., and Gatenholm, P. (2003). Effect of acetylation on the material properties of glucuronoxylan from aspen wood. Carbohydr. Polym. 52, 359-366.

Hayashi, T. (1989). Xyloglucans in the primary-cell wall. Ann. Rev. Plant Physiol. Plant Mol. Biol. 40, 139-168.

Helle, S., Cameron, D., Lam, J., White, B., and Duff, S. (2003). Effect of inhibitory compounds found in biomass hydrolysates on growth and xylose fermentation by a genetically engineered strain of S.cerevisiae. Enzyme Microb. Technol. 33, 786-792.

Holtzapple, M. T., and Chang, V. S. (2000). Fundamental factors affecting biomass enzymatic reactivity. Appl. Biochem. Biotechnol. 84-86, 5-37.

Jacobs, A., Lundqvist, J., Stalbrand, H., Tjerneld, F., and Dahlman, O. (2002). Characterization of watersoluble hemicelluloses from spruce and aspen employing SEC/MALDI mass spectroscopy. Carbohydr. Res. 337, 711-717.

Jia, Z., Cash, M., Darvill, A. G., and York, W. S. (2005). NMR characterization of endogenously $\mathrm{O}$ acetylated oligosaccharides isolated from tomato (Lycopersicon esculentum) xyloglucan. Carbohydr. Res. 340, 1818-1825

Kabel, M. A., de Waard, P. D., Schols, H. A., and Voragen, A. G. J. (2003). Location of $\mathrm{O}$-acetyl substituents in xylo-oligosaccharides obtained from hydrothermally treated eucalyptus wood. Carbohydr. Res. 338 69-77.

Kabel, M. A., Van Den Borne, H. Vincken, J.-P., Voragen, A. G. J., and Schols, H. A. (2007). Structural differences of xylans affect their interaction with cellulose. Carbohydr. Polym. 69, 94-105.

Kong, F. R., Engler, C. R., and Soltes, E. J. (1992). Effects of cell-wall acetate, xylan backbone, and lignin on enzymatic-hydrolysis of aspen wood. Appl. Biochem. Biotechnol. 34-35, 23-35.

Konn, J., Vahasalo, L., Pranovich, A., and Holmbom, B. (2006). De-esterification and sulfonation in spruce CTMP: effects on pulp and paper properties. Holzforschung 60 355-364.

Kormelink, F. J. M., Lefebvre, B., Strozyk, F., and Voragen, A. G. J. (1993). Purification and characterization of an acetyl xylan esterase from Aspergillus niger. J. Biotechnol. 27, 267-282.

Koseki, T., Miwa, Y., Akao, T. Akita, O., and Hashizume, K. (2006). An Aspergillus oryzae acetyl xylan esterase: molecular cloning and characteristics of recombinant enzyme expressed in Pichia pastoris. J. Biotechnol. 121, 381-389.

Koseki, T., Miwa, Y., Fushinobu, S., and Hashzume, K. (2005). Biochemical characterization of recombinant acetyl xylan esterase from Aspergillus awamori expressed in
Pichia pastoris: mutational analysis of catalytic residues. Biochim. Biophys. Acta 1749, 7-13.

Laffend, K. (1967). Effect of Acetyl Content of Glucomannan on its Sorption onto Cellulose and its Beater Addi tive Properties I. Effect on Sorption. Ph.D. thesis, Lawrence University, Wisconsin, USA, Institute of Paper Chemistry, pp. 90

Lee, C., Teng, Q., Zhong, R., and Ye, Z.-H. (2011). The four Arabidopsis REDUCED WALL ACETYLATION genes are expressed in secondary wall-containing cells and required for the acetylation of xylan. Plant Cell Physiol. 52, 1289-1301.

Li, X-L., Skory, C. D., Cotta, M. A., Puchart, V., and Biely, P. (2008). Novel family of carbohydrate esterase, based on identification of the Hypocrea jecorina acetyl esterase gene. Appl. Environ. Microbiol. 74, 7482-7489.

Linden, J. C., Decker, S. R., Samara, M., (1994). "Role of acetyl esterase in biomass conversion," in Enzymatic Conversion of Biomass For Fuels Production, Vol. 566, ACS Symposium Series, eds M. E. Himmel, J. O. Baker, and R. P. Overend (Fort Collins: American Chemical Society) 452-467.

Liners, F., Gaspar, T., and Cutsem, P. V. (1994). Acetyl and methyl esterification of pectins of friable and compact sugar-beet calli: consequences for intercellular adhesion. Planta 192, 545-556.

Lisperguer, J., Droguett, C., Ruf, B., and Nunez, M. (2007). The effect of wood acetylation on thermal behavior of wood-polystyrene composites. J. Chil. Chem. Soc. 52, 1073-1075.

MacKinnon, I. M., Jardine, W. G., O'Kennedy, N., Renard, C. G. M. C., and Jarvis, M. C. (2002). Pectin and non-methyl esters in potato cell walls. J. Agric. Food Chem. 52, 342-346.

Maiorella, B., Blanch, H. W., and Wilke, C. R. (1983). By-product inhibition effects on ethanolic fermentation by Saccharomyces cerevisiae. Biotechnol. Bioeng. 25, 103-121.

Manabe, Y., Nafisi, M., Verhertbruggen, Y., Orfila, C., Gille, S., Rautengarten, C., etal. (2011). Loss-offunction mutation of REDUCED WALL ACETYLATION2 in Arabidopsis leads to reduced cell wall acetylation and increased resistance to Botrytis cinerea. Plant Physiol. 155, 1068-1078.

Margolles-Clark, E., Tenkanen, M. Soderlund, H., and Penttila, M.
(1996). Acetyl xylan esterase from Trichoderma reesei contains an activesite serine residue and a cellulosebinding domain. Eur. J. Biochem. 237, 553-560.

Martinez-Martinez, I., NavarroFernandez, J., Lozada-Ramirez, J. D., Garcia-Carmona, F., and SanchezFerrer, A. (2008). YesT: a new rhamnogalacturonan acetyl esterase from Bacillus subtilis. ProteinsStruct. Funct. Bioinformat. 71, 379-388.

Mastihubová, M., and Biely, P. (2004). Lipase-catalysed preparation of acetates of 4-nitrophenyl B-Dxylopyranoside and their use in kinetic studies of acetyl migration. Carbohydr. Res. 339, 1353-1360.

Mohebby, B. (2003). Biological Attack of Acetylated Wood. Ph.D. thesis, Georg August Universität, Göttingen.

Molgaard, A., Kauppinen, S., and Larsen, S. (2000). Rhamnogalacturonan acetylesterase elucidates the structure and function of a new family of hydrolases. Structure 8, 373-383.

Montanier, C., Money, V. A., Pires, V. M. R., Flint, J. E., Pinheiro, B. A., Goyal, A., et al. (2009). The active site of a carbohydrate esterase displays divergent catalytic and noncatalytic binding functions. PLoS Biol. 7:e1000071. doi: 10.1371/journal.pbio.1000071

Naran, R., Black, S., Decker, S. R., and Azadi, P. (2009). Extraction and characterization of native heteroxylans from delignified corn stover and aspen. Cellulose 16, 661-675.

Navarro-Fernandez, J., MartinezMartinez, I., Montoro-Garcia, S., Garcia-Carmona, F., Takami, H., and Sanchez-Ferrer, A. (2008). Characterization of a new rhamnogalacturonan acetyl esterase from Bacillus halodurans C-125 with a new putative carbohydrate binding domain. J. Bacteriol. 190, 1375-1382.

Olsson, L., and Hahn-Hägerdal, B. (1996). Fermentation of lignocellulosic hydrolysates for ethanol production. Enzyme Microb. Technol. 18, 312-331.

O’Neill, M. A., Ishii, T., Albersheim, P., and Darvill, A. G. (2004). II: structure and function of a borate cross-linked cell wall pectic polysaccharide. Annu. Rev. Plant Biol. 55, 109-139.

Orfila, C., Dal Degan, F., Jorgensen, B., Scheller, H. V., Ray, P. M., and Ulvskov, P. (2012). Expression of mung bean pectin acetyl esterase in potato tubers: effect on acetylation of cell wall polymers and tuber mechanical properties. Planta 236, 185-196. 
Papadopoulos, A. N., and Pougioula, G. (2010). Mechanical behaviour of pine wood chemically modified with a homologous series of linear chain carboxylic acid anhydrides. Bioresour. Technol. 101, 6147-6150.

Pauly, M. (1999). Development of Analytical Tools to Study Plant Cell Wall Xyloglucan. Ph.D. thesis, Shaker Verlag, Aachen.

Pauly, M., and Scheller, H. V. (2000). O-acetylation of plant cell wall polysaccharides: identification and partial characterization of a rhamnogalacturonan O-acetyl-transferase from potato suspension-cultured cells. Planta 210, 659-667.

Peterson, M. D., and Thomas, R. J. (1978). Protection of wood from decay fungi by acetylation - an ultrastructural and chemical study. Wood Fiber 10, 149-163.

Pogorelko, G., Fursova, O., Lin M., Pyle, E., Jass, J., and Zabotina, O. A. (2011). Post-synthetic modification of plant cell walls by expression of microbial hydrolases in the apoplast. Plant Mol. Biol. 77, 433-445.

Pogorelko, G., Lionetti, V., Fursova, O., Sundaram, R. M., Qi, M., Whitham, S. A., et al. (2013). Arabidopsis and Brachypodium transgenic plants expressing $A$. nidulans acetylesterases have decreased degree of polysaccharide acetylation increase resistance to pathogens. Plant Physiol. (in press).

Poutanen, K., Sundberg, M., Korte, H., and Puls, J. (1990). Deacetylation of xylans by acetyl esterases of Trichoderma reesei. Appl. Microbiol. Biotechnol. 33, 506-510.

Ralet, M. C., Cabrera, J. C., Bonnin, E., Quéméner, B., Hellín, P., and Thibault, F. (2005). Mapping sugar beet pectin acetylation pattern. Phytochemistry 66, 1832-1843.

Ralet, M. C., Crepeau, M. J., and Bonnin, E. (2008). Evidence for a blockwise distribution of acetyl groups onto homogalacturonans from a commercial sugar beet (Beta vulgaris) pectin. Phytochemistry 69, 1903 1909.

Ralet, M. C., Crepeau, M. J., Buchholt, H. C., and Thibault, J. F. (2003). Polyelectrolyte behaviour and calcium binding properties of sugar beet pectins differing in their degrees of methylation and acetylation. Biochem. Eng. J. 16, 191-201.

Ramsden, M. J., Blake, F. S. R., and Fey, N. J. (1997). The effect of acetylation on the mechanical properties, hydrophobicity, and dimensional stability of Pinus sylvestris. Wood Sci. Technol. 31, 97-104.

Ranatunga, T. D., Jervis, J., Helm, R. F., Mcmillan, J. D., and Hatzis, C. (1997) Identification of inhibitory components toxic toward Zymomonas mobilis CP4(pZB5) xylose fermentation. Appl. Biochem. Biotechnol. 67, 185-198.

Rowell, R. M. (2009). Acetylation of wood. Forest Prod. J. 56, 4-11.

Schols, H. A., Geraeds, C., Searlevanleeuwen, M. F., Kormelink, F. J. M., and Voragen, A. F. J. (1990). Hairy (ramified) regions of pectins. 2. Rhamnogalacturonase - a novel enzyme that degrades the hairy regions of pectins. Carbohydr. Res. 206, 105-115.

Selig, M. J., Adney, W. S., Himmel, M. E., and Decker, S. R. (2009). The impact of cell wall acetylation on corn stover hydrolysis by cellulolytic and xylanolytic enzymes. Cellulose 16, 711-722.

Shao, W. L., and Wiegel, J. (1995). Purification and characterization of 2 thermostable acetyl xylan esterases from thermoanaerobacterium sp strain-jw/sl-ys485. Appl. Environ. Microbiol. 61, 729-733.

Shevchik, V. E., and Hugouvieux-CottePattat, N. (1997). Identification of a bacterial pectin acetyl esterase in Erwinia chrysanthemi 3937. Mol. Microbiol. 24, 1285-1301.

Shevchik, V. E., and Hugouvieux-CottePattat, N. (2003). PaeX, a second pectin acetylesterase of Erwinia chrysanthemi 3937. J. Bacteriol. 185, 3091-3100.

Sjöström, E. (1993). Wood Chemistry: Fundamentals and Applications. New York: Academic Press.

Sumi (1964). Accessibility of wood and wood carbohydrates measured with titriated water. Tappi J. 47, 4.

Sundberg, M., and Poutanen, K. (1991). Purification and properties of two acetylxylan esterases of Trichoderma reesei. Biotechnol. Appl. Biochem. 13, 1-11.

Taylor, E. J., Gloster, T. M., Turkenburg, J. P., Vincent, F., Brzozowski, A. M., Dupont, C., et al. (2006). Structure and activity of two metal ion-dependent acetylxylan esterases involved in plant cell wall degradation reveals a close similarity to peptidoglycan deacetylases. J. Biol. Chem. 281, 10968-10975.
Teleman, A., Lundqvist, J., Tjerneld, F., Stalbrand, H., and Dahlman, O. (2000). Characterization of acetylated 4-O-methylglucuronoxylan isolated from aspen employing $\mathrm{H}-1$ and C-13 NMR spectroscopy. Carbohydr. Res. 329, 807-815.

Teleman, A., Nordstrom, M., Tenkanen, M., Jacobs, A., and Dahlman, O. (2003). Isolation and characterization of $\mathrm{O}$-acetylated glucomannans from aspen and birch wood. Carbohydr. Res. 338, 525-534.

Teleman, A., Tenkanen, M., Jacobs, A., and Dahlman, O. (2002). Characterization of O-acetyl-(4O-methylglucurono) xylan isolated from birch and beech. Carbohydr. Res. 337, 373-377.

Tenkanen, M. (1995). Characterization of esterases acting on hemicelluloses. Ph.D. thesis, Helsinki University of Technology, Finland, VTT Publications, 242, pp. 94.

Tenkanen, M., Thornton, J., and Viikari, L. (1995). An acetylglucomannan esterase of Aspergillus oryzae - purification, characterization and role in the hydrolysis of O-acetylgalactoglucomannan. J. Biotechnol. 42, 197-206.

Timell, T. E. (1967). Recent progress in the chemistry of wood hemicelluloses. Wood Sci. Technol. 1, 45-70.

Topakas, E., Kyriakopoulos, S., Biely, P., Hirsch, J., Vafiadi, C., and Christakopoulos, P. (2010). Carbohydrate esterases of family 2 are 6-O-deacetylases. FEBS Lett. 584, 543-548.

Vazquez, M. J., Alonso, J. L., Dominguez, H., and Parajo, J. C. (2001). Production of xylose-containing fermentation media by enzymatic posthydrolysis of oligomers produced by corn cob autohydrolysis. World J. Microbiol. Biotechnol. 17, 817-822.

Voragen, A. G. J., Schols, H. A., and Pilnik, W. (1986). Determination of the degree of methylation and acetylation of pectins by H.P.L.C. Food Hydrocoll. 1, 65-70.

Willför, S., Sjoholm, R., Laine, C., Roslund, M., Hemming, J., and Holmbom, B. (2003). Characterisation of water-soluble galactoglucomannans from Norway spruce wood and thermomechanical pulp. Carbohydr. Polym. 52, 175-187.

Williamson, G. (1991). Purification and characterization of pectin acetylesterase from orange peel. Phytochemistry 30, 445-449.
Xiong, G., Cheng, K., and Pauly, M. (2013). Xylan O-acetylation impacts xylem development and enzymatic recalcitrance as indicated by the Arabidopsis mutant tbl29. Mol. Plant (in press).

Yoshida, S., Mackie, R. I., and Cann, I. K. O. (2010). Biochemical and domain analyses of FSUAxe6B, a modular acetyl xylan esterase, identify a unique carbohydrate binding module in Fibrobacter succinogenes S85. J. Bacteriol. 192, 483-493.

Zanuttini, M., Marzocchi, V., Citroni, M., and Mocchiutti, R. (2003). Alkali impregnation of hardwoods. Part 1: moderate treatment of poplar wood. J. Pulp Pap. Sci. 29, 313-317.

Zanuttini, M., Marzocchi, V., Mocchiutti, P., and Inalbon, M. (2005). Deacetylation consequences in pulping processes. Holz Als Roh-Und Werkstoff 63, 149-153.

Zhang, J., Siika-Aho, M., Tenkanen, M., and Viikari, L. (2011). The role of acetyl xylan esterase in the solubilization of xylan and enzymatic hydrolysis of wheat straw and giant reed. Biotechnol. Biofuels 4, 60 .

Conflict of Interest Statement: The authors declare that the research was conducted in the absence of any commercial or financial relationships that could be construed as a potential conflict of interest.

Received: 23 February 2013; accepted: 15 April 2013; published online: 21 May 2013.

Citation: Pawar PM-A, Koutaniemi S, Tenkanen M and Mellerowicz EJ (2013) Acetylation of woody lignocellulose: significance and regulation. Front. Plant Sci. 4:118. doi: 10.3389/fpls.2013.00118

This article was submitted to Frontiers in Plant Biotechnology, a specialty of Frontiers in Plant Science.

Copyright (c) 2013 Pawar, Koutaniemi, Tenkanen and Mellerowicz. This is an open-access article distributed under the terms of the Creative Commons Attribution License, which permits use, distribution and reproduction in other forums, provided the original authors and source are credited and subject to any copyright notices concerning any thirdparty graphics etc. 